\title{
Correction to: Moral Burden of Bottom-Line Pursuits: How and When Perceptions of Top Management Bottom-Line Mentality Inhibit Supervisors' Ethical Leadership Practices
}

\author{
Rebecca L. Greenbaum ${ }^{1}$ [D $\cdot$ Mayowa T. Babalola ${ }^{2} \cdot$ Matthew J. Quade ${ }^{3} \cdot$ Liang Guo $^{4} \cdot$ Yun Chung Kim ${ }^{5}$
}

Published online: 13 July 2020

(c) Springer Nature B.V. 2020

\section{Correction to: Journal of Business Ethics https://doi.org/10.1007/s10551-020-04546-w}

The name of the first author was incorrect in the initial online publication. The original article has been corrected.

Publisher's Note Springer Nature remains neutral with regard to jurisdictional claims in published maps and institutional affiliations.

The original article can be found online at https://doi.org/10.1007/ s10551-020-04546-w.

Rebecca L. Greenbaum

rebecca.greenbaum@ rutgers.edu

1 School of Management and Labor Relations, Rutgers

University, 94 Rockafeller Road, Piscataway, NJ 08854, USA

2 United Arab Emirates University, Abu Dhabi, UAE

3 Baylor University, Waco, USA

4 Shandong University at Weihai, Weihai, China

5 Oklahoma State University, Stillwater, USA 